\title{
Fechamento de subtópicos em diálogos assimétricos
}

Sigrid Castro Gavazzi Universidade Federal Fluminense

\section{Abstract}

This essay classifies sub-topic closing in two categories: the phrastic, in which the discurse sections are developed in a linear manner, in contrast with the paraphrastic, in which the rhetorical closing recycles the previous information. The data are then subjected to a computational programme which selects factors, which determine the same paraphrastic closing: (-) world knowledge; (+) argumentation; (+) subjectivity; (+) basic sentence; $(+)$ the female sex. 


\section{INTRODUÇÃO / OBJETIVOS}

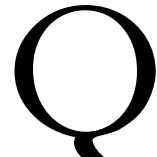

ualquer conversação assenta-se em estratégicas comunicativas específicas. Compor um relato, descrever um objeto, expor uma opinião exige o conhecimento de técnicas, que vão desde a escolha do material lingüístico, nos níveis de construção da sentença, à ordenação da mensagem. Assim a lógica faz crer que todos os falantes dominem tais artifícios, selecionando os recursos oferecidos, escalonando-os em graus de importância.

As táticas para a abertura e manutenção do turno já vêm sendo alvo de inúmeras pesquisas. No entanto, pouca atenção tem sido dada à conclusão. Na realidade, o esquecimento é injusto. Nas conversas, de um modo geral, o ouvinte anseia por uma finalização e, até por convenção social, só se deve tomar a palavra quando o outro tiver terminado sua preleção. Nas entrevistas, que ora estudamos, cabe então ao entrevistador, "perceber" a hora exata da proposta de nova questão.

Investigaremos, por conseguinte, as pistas desencadeadoras dessa "percepção". Possivelmente haverá, aliado a elementos extra e supralingüísticos, um conjunto de recursos textuais discursivos que funcione como indício para o entrevistador de que a conversa está "murchando" e necessita ser imediatamente reativada.

Deste modo, este ensaio pretende melhor conhecer parte do universo comunicativo que se desenvolve nas entrevistas, detectando e analisando as estratégias, sistematizadas, genéricas e regulares, constitutivas da "gramática" da finalização de um subtópico.

\section{PRESSUPOSTOS TEÓRICOS}

Para se compreender o uso da lingua na comunicação, é preciso estabelecer as correlações entre mecanismos formais/ 
gramaticais e os contextos discursivos em que aparecem. Em outros termos: proceder-se-á basicamente a uma análise descritiva e interpretativa do fenômeno em voga - fechamento de subtópicos em diálogos assimétricos - tendo sempre como base o texto, mas, sobretudo, sem perder de vista o contexto que o motivou.

Para tal, adotaram-se os princípios básicos de um funcionalismo moderado (Schiffrin, 1994) que estabelece seu escopo, segundo a especialista, sobretudo nas idéias de Brown \& Yule (1983), segundo as quais as formas lingüísticas só podem ser descritas se consideradas as relações de interdependência entre elas e suas finalidades/funções na vida do indivíduo. Considera-se, assim, que a codificação lingüística (e a conseqüente decodificação por parte do ouvinte) passaria por motivações específicas que só podem ser avaliadas em relação ao contexto situacional e interativo que as produziu. Como a finalização/ conclusão de um subtópico não se dá de modo abrupto, deve estar codificada em uma estrutura que ultrapasse os limites da sentença. A unidade formal de análise estudada, pois, expande-se além do espaço da sentença/frase. Em decorrência, ao requerer um conjunto textual mais extenso, sua apreensão será sustentada pela própria situação global de comunicação, onde se incluem, entre outros itens, os objetivos dos atos de fala, contexto, discurso, participantes.

Ainda na ampla linha funcionalista, a referida autora lembra, para este tipo de análise, das pertinentes contribuições de Gumperz (1982) - as interações, para ele, assumem caráter regular e freqüente, formando um esqueleto verbal de signos/código - e de Goffmann (1974), ao lançar a noção de "pista contextual" e potencializar o aspecto de "inferência contextual". Para o autor, o "eu individual" (social, cultural e lingüístico) constitui uma construção social (frame) ou, antes, uma contrução interativa, por meio da qual situações são definidas e interpretadas.

Como complemento indispensável, alinham-se alguns conceitos referentes à análise da conversação (Marcuschi, 1986), no entrecruzar de cláusulas e segmentos discursivos, contemplando a linearidade e a estrutura hierárquica do conhecimento/conteúdo 
tratado na interação. Procura, então, padrões recorrentes, distribuições e formas de organização da fala (Schiffrin, op.cit:236). Dados contextuais são considerados, porém em uma dimensão bem menos relevante que a que lhes é conferida na análise funcionalista. Fatores como sexo, faixa etária, idade, entre outros, podem se mostrar significativos em algum ponto da conversação, porém não com força suficiente para motivar/determinar estruturas. Ambas as linhas teóricas complementam-se, pois buscam o texto como bússola e mapa.

Como ferramenta complementar de trabalho, utilizamos o modelo variacionista laboviano, por intermédio do Pacote computacional VARBRUL (versão 1988). Cumpre notar que - apesar das inúmeras dificuldades já arroladas por inúmeros especialistas para o embricamento de uma análise eminentemente qualitativa com dados quantitativos - consideramos haver inúmeras vantagens para o estudioso, como a inclusão de parâmetros sociolingüísticos (como sexo e região geográfica, p.e.) e meio adequado para a descrição de quadros que se querem regulares.

\section{APARATO METODOLÓGICO}

Tomamos como corpus doze entrevistas, pertencentes ao acervo compartilhado do Projeto NURC/RJ. ${ }^{1}$ Contemplaram-se três capitais (Rio de Janeiro, Salvador e Porto Alegre), uma única faixa etária (36 a 55 anos), três informantes do sexo feminino e três, do masculino. Sexo e variação regional foram posteriormente testados como possíveis grupos condicionantes para determinado tipo de fecho.

O tipo de elocução estudado foram as entrevistas, ou diálogos assimétricos, ou no caso do Projeto em apreço, DIDs, anteriormente citados. Nestes inquéritos, mormente de cunho instrucional, cabe ao documentador proceder a certo número de questões - estabelecendo o "fio condutor" da entrevista acerca de um temário abrangente ou geral do inquérito (SUPERTÓPICO), como "Cidades e Comércio", "Alimentação" etc. O entrevistador acompanha o discurso-resposta do documentado e vai, paulatinamente, inserindo novas questões. No decorrer da entrevista, cabe-lhe, assim, perceber o momento adequado 
para a colocação de nova pergunta, solicitando maiores informes sobre o discorrido ou passando para novo tópico ou subtópico.

Observe-se que consideramos a noção de TÓPICO em sua acepção discursiva, ou seja, conjunto de enunciados a respeito de determinado conteúdo em certo momento do inquérito, sem necessidade de estar textualmente expresso. Configurar-se-ia, então, como uma estrutura de módulos conversacionais. Tais módulos - cujo fechamento é o objeto de nossa especulação - denominam-se SUBTÓPICOS (Fávero: 1993).

Cremos que o mapeamento abaixo ilustra bem um quadro tópico (supertópico, tópico, subtópico):

$\begin{array}{ll}\text { Supertópico } & - \text { Cidades e Comércio } \\ \text { Tópico 1 } & - \text { Casa da infância } \\ \text { Subtópico A } & - \text { Compra da casa } \\ \text { Subtópico B } & - \text { Descrição da casa } \\ \text { Subtópico C } & - \text { O quintal }\end{array}$

Após a separação em tópicos e subtópicos, destacaram-se, então, os trechos finais de cada um desses subtópicos, que correspon-deram aos 55 últimos vocábulos. Esses fragmentos foram por nós cognominados "fechamentos" ou "fechos". A contagem por vocábulos, se não valoriza o critério semântico-textual, homogeneíza os dados.

Exemplo:

Subtópico - Compra da casa

todo o madeirame... e o meu pai não era homem rico, meu pai era funcionário público... ele tinha doze filhos, você imagina... doze filhos e tinha que criar aquela garotada toda... mas mesmo assim pôde comprar essa casa... ele comprou essa casa... essa casa, essa casa própria e ele depois vendeu pra esse tal.. por essa fortuna (f.1)

A partir daí, compararam-se os fechos.

\section{DOIS TIPOS BÁSICOS DE FECHO: O CENÁRIO No 1}

Confrontando-se os fechos, detectamos dois tipos, em relação de oposição. 


\subsection{Fecho frástico}

Ocorre em 40\% dos casos. Nele, as porções de texto emitidas, por elas mesmas, encaminham o assunto para determinada finalização. Aproxima-se bastante do que Labov (1979) denominou "resultado" para as narrativas que, marcadas por forte seqüencialidade, soliticam uma conclusão, necessária ao entendimento. Tanto que, como não há história sem final, seu fecho não tem suscitado maiores elucubrações por parte dos teóricos que a estudam. Também no fecho em pauta, os segmentos discursivos encaminham o conteúdo para determinado final, sem ralentamentos. Veja-se o exemplo:

Subtópico - Refeições: horário/tipo de alimento utilizado pela manhã, incluindo, nesse caso, vamos dizer, bifes, mal-passado, etc, com legumes, frutas e sucos de frutas e, como bom brasileiro, não se deixa de tomar um pequeno cafezinho. O almoço geralmente eu faço tipo lanche: é mais ligeiro do que a refeição da manhá. E à noite, apenas nós usamos queijo e café (f. 111)

São fechos que respondem, geralmente, a perguntas esperadas em determinado tema, i.e., mais objetivas, que correspondem à expectativa gerada pelo próprio assunto em pauta. Conseqüentemente, as respostas (e seu respectivo fechamento) centram-se praticamente apenas no campo semântico enfocado e o grau de subjetividade do enunciado geralmente é mínimo. Fora essas observações, encontramos nos frásticos também uma finalização prosodicamente descendente, ${ }^{2}$ uma intenção direta, do tipo "ponto final/acabou-se meu turno" e ausência de marcas (morfossintáticas) específicas - como as verificadas no parafrástico.

\subsection{Fecho parafrástico}

Constitui mais da metade das ocorrências (60\%). Tal fato, realmente, não causa surpresa: a recorrência, como processo discursivo útil, parece adequada a términos de assunto: se um subtópico 
vai-se esgotando, possivelmente faltem idéias para sustentá-lo. Por conseguinte, seu próprio esvaziamento seria preenchido pela reiteração de cláusulas/idéias, promovendo a eficácia interativa. Apresenta-se, desta forma, como um “... dos mecanismos de composição do texto e condução do tópico discursivo” (Marcuschi, 1990:1), estratégia de monitoração, favorecedora da coesão e, conseqüen-temente, da própria organização discursiva.

Observe-se o exemplo:

Subtópico - Refrigerantes

meu cunhado também toma refrigerante... eles tomam muita cocacola... nós todos, sabe... então aí eu tomo um pouquinho de cocacola... mas também não, não... é o que eu digo a você, tudo é uma questão de hábito, como eu não tenho por hábito... eu não sinto muito falta, entendeu? e até às vezes nem gosto muito... // mas normalmente a gente tom a coca-cola aqui em casa...// (f.49)

Assim, reconstruindo uma matriz em um enunciado derivado e oscilando "...entre a reprodução pura e simples do conteúdo e sua reformulação" (Koch et al, 1990:166), os fechamentos que se utilizam da paráfrase - daí denominados "parafrásticos" - foram divididos em quatro categorias, seguindo uma escalaridade semântica, que vai do menos elaborado mentalmente (fecho explícito) ao mais refinado (fecho resumitivo).

Sua distribuição no corpus se observa no quadro abaixo:

$\begin{array}{ll}\text { EXPLÍCITO } & 12 \% \\ \text { REDUPLICATIVO } & 24 \% \\ \text { ANALÍTICO } & 14 \% \\ \text { ANALÍTICO-RESUMITIVO } & 10 \%\end{array}$

A - EXPLÍCITO: o documentado declara, de modo claro (daí "explícito") que não deseja continuar com o subtópico proposto, seja por desagrado seja por não se sentir capacitado para sobre ele discorrer. 
Subtópico-Material escolar

Olha ... eu tenho a impressão que devia ser uma professora que era encarregada... ou era uma aluna... então eu ... eu, eu suponho... que a professora devia pegar um em cada turma, né, um aluno...// Ah... não tenho idéia não... já são muitos anos, né? // (fech.56)

O advérbio NÃO se encontra presente em 94,8\% dos casos. Além disso, tal tipo de fecho incide muito mais no discurso argumen-tativo do que no narrativo e há tendência a vir sinalizado por marca-dor de apoio contrastivo. Vejam-se as finalizações abaixo.

... existem muitos outros aí, mas honestamente eu sou muito fraca em matéria de condimentos, sabe? (f.134)

(...) agora honestamente, com essa nomenclatura, não sei lhe dizer... entende? (f. 118)

B - REDUPLICATIVO: verifica-se a repetição, idêntica ou com pequenas alterações, de informação passada. Existe, então, alta cooperatividade interacional e o trabalho interpretativo do entrevistador fica um pouco mais reduzido do que no analítico ou no resumitivo, por exemplo. O falante usa a primeira porção discursiva como indício para o término do fecho. Para ele, a informação aí textualizada mostra-se relevante, deve ser mantida na memória e, quando reiterada, fecha-se a subunidade. Observe-se o subtópico abaixo:

Subtópico - Compras em geral

... a própria organização social que nós temos é que leva a isso... então a mulher é mais levada a comprar... a prover, a casa e tal... que é obrigação dela, não é ? Geralmente na divisão do trabalho é isso... está se modificando muito... mas ainda é muito assim... então ela é mais levada a comprar, se habitua a comprar (fech.27)

C - ANALÍTICO: o documentador realiza uma avaliação sobre o que vinha discorrendo, interpretando a questão formulada. Emite opiniões e, sobretudo, juízos de valor de forma mais (ou menos) imparcial. Veja-se: 
Subtópico - Alimentação em outros estados

... outro dia eu estive tentando comprar uma... eram quinze cruzeiros uma fruta-de-conde... eu até desisti... então lá.. lá tem com uma tranqüilidade que você encontra fruta-de-conde a cada passo que você dá... agora... realmente... a alimentação de outros estados é bem diferente daqui do Rio, sabe? (f.34)

Neste tipo de fecho:

a) há grande freqüência de expressões do tipo "eu acho", "eu tenho a impressão" (formas de que o falante faz uso para expressar um conteúdo quase certo, próximo da verdade, mais como uma hipótese que depende de confirmação)

(...) eu acho então que hoje é muito mais interessante a gente ser criança do que no meu tempo (f.51)

b) marcadores conversacionais/modalizadores em geral (então/aí, mas/agora, vamos dizer/quer dizer, aliás, real-mente/ francamente)

(...) francamente... eu não, eu não tenho a menor saudade da infância... (f. 58)

c) verbo ser/cópula e ampla adjetivação.

O verbo SER/cópula retrata bem uma das estruturas típicas desse tipo de fecho - quando o informante, após detalhar alguma situação ou caso, expressa sua opinião utilizando uma predicação de cunho generalizante. Produz, na avaliação, efeito globalizante e atenua uma possível "falta de vocabulário". Acompanha-o um adjetivo em 92,3\% dos casos. Veja-se:

(após enumerar tudo que lhe desagrada, no Rio)

(...) O Rio de Janeiro é uma cidade bastante inóspita... (f.8)

(após relatar condições agradáveis de um shopping-center)

(...) então é um convite pra compra tremendo! (f.31) 
D - ANALÍTICO-RESUMITIVO: O documentado utiliza-se de termos organizadores para sintetizar seu próprio discurso anterior. Ou seja: reúne elementos diversos e os reorganiza em uma nova estrutura ou configuração.

Subtópico - Acompanhamentos

... preferivelmente batatas fritas né?... ou então pode ser também o bife a cavalo, bife com ovo né? ou então... o bife com salada... são os três tipos de acompanhamento para o coitado do meu bife... (f.267)

Os artifícios utilizados inserem-se em duas categorias principais: uso de pronomes demonstrativos em função anafórica ou de um item lexical específico. Em menor escala, encontram-se também orações clivadas. Os exemplos abaixo ilustram o fato:

1) "então a gente sempre faz isso aí..." (f.251)

2) /depois de enumerar verduras que se usam em um cozido/ "Ah... toda verdura se pode colocar no cozido..." (f.133)

\section{ANÁLISE QUANTITATIVA: O CENÁRIO No 2}

Para este ensaio, consideramos como variável-dependente o tipo de fecho, i.e., a alternância entre o frástico e o parafrástico, tomando o último como aplicação da regra-variável.

Controlamos as seguintes variáveis: tipologia discursiva, mudanças na estrutura textual-discursiva (de tipo discursivo, de referente tópico), retomada de pauta discursiva principal, marcadores conversacionais, conhecimento do mundo, grau de subjetividade do enunciado), composição do período, sexo e região geográfica.

Com um input inicial de .065 favorável ao uso de fechos parafrásticos, o programa selecionou, em ordem de importância para a aplicação da regra, cinco grupos de fatores, explicitados a seguir. Categorizações menos transparentes foram exemplificadas.

$1^{\circ}$ ) Conhecimento do mundo

Diz respeito à expectativa de resposta gerada por cada subtópico. Como nesse tipo de entrevista (DID) o informante escolhe o 
supertópico sobre o qual será questionado e o documentador faz uso de roteiro exploratório (previamente preparado), espera-se que cada questão seja preenchida de modo satisfatório em termos de conteúdo (conhecimento + esperado). De modo geral, os subtópicos revestemse de maior simplicidade e não despertam maiores explanações. Observe-se:

Subtópico - Boletim meteorológico

Ora, eles informam a temperatura e informam o, a., a proba... a probabilidade do dia seguinte de haver chuva ou não, no país inteiro, separando por áreas: Norte, Nordeste, Leste, Sul, Centro-Oeste. (f.165)

Por vezes, entretanto, entremeia-se a resposta com relatos pessoais, adjunções, digressões, exemplos vários, afastando-se um pouco de uma tessitura que só se preocuparia em preencher semanticamente uma questão (conhecimento +/- esperado). É o caso a seguir:

Subtópico - Recordações da infância na escola

... havia consideração conosco... vamos dizer... mãe professora... amiga de professora... dona Ofélia... deve conhecer de nome... né... dona Ofélia era professora do Nilo Peçanha.. foi professora de minha irmã, muito amiga de mamãe... então havia uma... uma certa consideração conosco... você entende, né? (f.52)

Finalmente, há casos em que o documentado não sabe, não quer responder ou, mesmo, por razões pessoais, esquiva-se do roteiro "pré-fixado" (conhecimento - esperado). Veja-se:

Subtópico - Termômetro

Numa escala. Existem ao que... quando eu me... quando estudei, me lembro bem, existiam duas escalas, né? Era ... cen... centí... centí... centígrado e... cujo o máximo era... era... e tinha uma cujo máximo era o de oitenta. Richter. Ah... ah... Não me lembro, mesmo. (f.217)

$2^{\circ}$ ) Tipologia discursiva

Optamos pela classificação apresentada por Silva \& Macedo (1989), adaptando-a às necessidades deste estudo. Assim, opõem-se narrativas, relatos verbais de fatos e histórias (e descrições de vida) à 
argumentação, exposição de pontos de vista e opiniões (junto a descrições e receitas).

$3^{\circ}$ ) Grau de subjetividade do enunciado

Verifica-se se o documentado escolhe o caminho da menor ou da maior subjetividade, do maior ou do menor envolvimento. Como determinar "envolvimento/subjetividade" configura campo semântico escorregadio, optamos por uma análise empírica. Considera-se, portanto, haver + envolvimento quando o documentado, em suas declarações, não se furta a expor seus sentimentos, expressar conselhos, desejos, deixar claro que a opinião defendida é de sua "responsabilidade" (exemplo 1). Em contrapartida, enunciados menos subjetivos fornecem exposição o mais possível objetiva, fidedigna, impessoal (exemplo 2).

(1) Gosto de cinema. Mas ultimamente eu tenho ido muito pouco ao cinema, as atividades não me permitem, né? Eu fico cansado e à noite eu prefiro ir pra... assim prum restaurante do que ir a um cinema. Acho mais gostos, me distraio mais. (f.105)

(2) ... tem os clubes sociais que nós podemos, pode-se... Geralmente há reuniões entre os amigos, etc e tal.. E, durante a noite... tem a, a... um número enorme, considerável de boates funcionando. (F.106)

$4^{\text {o }) ~ C o m p o s i c ̧ a ̃ o ~ d o ~ p e r i ́ o d o ~}$

Detectamos os dois tipos básicos de estrutura sintático-oracional: o superoracional ("período composto") e o oracional ("período simples").

$5^{\circ}$ ) Sexo

O resultado estatístico encontra-se na tabela a seguir:

CONHECIMENTO DO MUNDO

$\begin{array}{lccc} & \text { apl. / total } & \% & \text { PR } \\ + \text { esp. } & 29 / 110 & 26 \% & .16 \\ + \text { - - esp. } & 95 / 119 & 80 \% & .67 \\ \text { - esp. } & 37 / 39 & 95 \% & .97\end{array}$




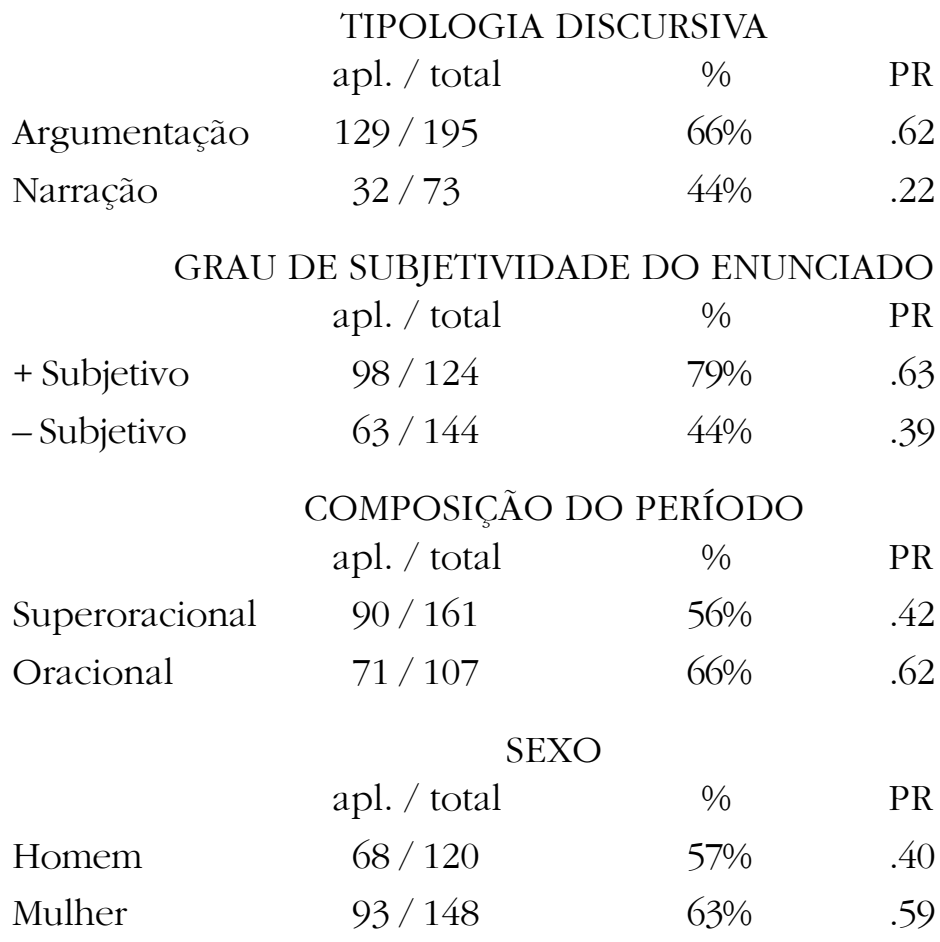

SIGNIFICÂNCIA: .028

A seleção revela alguns fatos. Aponta, então, para um ambiente favorável ao uso de fechos parafrásticos quanto mais presentes estiverem os seguintes aspectos:

a. O conbecimento do mundo entre documentado e documentador é mínimo, acarretando a necessidade de reformulações parafrásticas, um dos mecanismos de entendimento mútuo sobre o que se pauta na conversação;

b. O discurso se consubstanciaria por meio da modalidade argumentativa. Ora, ao ser entrevistado instrucionalmente, o falante tem de expor suas opiniões, porém, igualmente, deve persuadir seu entrevistador acerca do "teor de verdade" sobre os pontos de vista expostos; 
c. A subjetividade que sobressai no enunciado confirma também nossa hipótese anterior: quanto menos transparente se mostrasse um enunciado, mais chances de se encontrarem fechos parafrásticos;

d. A preferência pela composição do período em bases mais simples também não causa estranheza. A paráfrase, nesta tese, sempre foi focalizada como um procedimento que exigiria esforço cognitivo maior do que uma exposição mais linear, sem ralentamentos. Assim, o falante procura assentar seu enunciado em um esqueleto sintático com maior simplicidade;

e. Finalmente, o sexofeminino desponta como aquele que reformula seu pensamento com maior freqüência para fechar subunidades. Como a mulher apresenta tendência ao respeito às normas gramaticais (de maior prestígio social), poderíamos supor também que observasse de forma mais apurada, também, as regras interacionais na facilitação da compreensão da mensagem, daí utilizando mais a recorrência.

\section{CONCLUSÃO}

O fecho - ou fechamento - realmente é uma constante, um aspecto genérico da língua em uso. Esboça-se, na superfície, por meio de "pistas" que, reunidas, levam, senão a um modelo, pelo menos ao entendimento da codificação lingüística da codificação. Detectados, então, os dois tipos básicos de fecho, não creditávamos a nenhum dos dois caráter aleatório ou escolha assistemática por parte dos falantes. E, em busca das condições regulares que levariam à tendência de uso de cada um dos tipos, localizamos as condições textuais-discursivas favorecedoras, testadas por programa computacional. Mas o processo deve ainda suscitar outras 
especulações. Novos estudos, resultantes de indagações várias por certo advirão, no (sempre) ensaio de elucidar pontos ainda "descosturados", ou que prescindam de maior respaldo teórico ou, ainda, que reclamem um espaço temporal maior para um mapeamento mais detalhado. Enfim, um campo aberto para a reflexão sobre o discurso, sobre a conversação, sobre o próprio homem, em seus modos de pensar, organizar suas idéias, fazer-se entender e ser entendido pelo outro.

\section{NOTAS}

${ }^{1}$ Este Projeto, hoje conhecido nacionalmente, tem o “...intuito de depreender a norma idiomática fundada no uso real da língua” (Cunha, 1989:11) em cinco capitais brasileiras. Pesquisa-se a norma culta oral, tomando-se por critérios o sexo dos informantes, três faixas etárias e três tipos de interação verbal: Os DIDS (Diálogos Informais entre Informante e Documentador), as Elocuções Formais (como aulas e palestras, por exemplo) e os D2s (Diálogos entre Dois Informantes).

${ }^{2} \mathrm{O}$ aspecto prosódico da existência de uma curva melódica descendente nesse tipo de fechamento será tratado em ensaio posterior.

\section{REFERÊNCIAS BIBLIOGRÁFICAS}

BROWN, G., YULE, G. Discourse analysis. Cambridge: Cambridge University Press, 1983.

CUNHA, Celso. Objetivos do Projeto NURC. IN: CASTILHO, Ataliba Teixeira de. Português culto falado no Brasil. Campinas: Ed. Da UNICAMP, 1989.

FÁVERO, Leonor Lopes. O tópico conversacional. In: PRETI, Dino (org.) Análise de textos orais. São Paulo: FFLCH/USP, 1993.

GAVAZZI, Sigrid Castro. Fechamentos de subtópicos em diálogos assimétricos. Rio de Janeiro: UFRJ, Faculdade de Letras, 1995. 262 fl. mimeo. Tese de Doutorado em Língua Portuguesa.

GOFFMAN, E. Frame Analysis. New York: Harper and Row, 1974. Mimeo.

GUMPERZ, J. Discourse Strategies. Cambridge. Mimeo.

$\mathrm{KOCH}$, Ingedore Villaça et al. Aspectos do processamento do fluxo da informação no discurso oral dialogado. In: CASTILHO, Ataliba Teixeira de. (Org). Gramática do Português Falado: a ordem. Campinas, UNICAMP/FAPESP, 1990. 
LABOV, S.Y. Language in the inner City: studies in the black english vernacular. Filadelfia: Pensilvania Press, 1972.

MARCUSCHI, Luiz Antônio. Análise da Conversação. São Paulo: Ática, 1986. . A repetição na língua falada: formas e funções. Recife, Universidade Federal de Pernambuco, 1992. 196 fl. mimeo.

PINTZUK, Susan. VARBRUL Programs. 1988. Mimeo.

SILVA, Giselle M. De Oliveira, MACEDO, Alzira Tavares de. Análise sociolingüística de alguns marcadores conversacionais. Rio de Janeiro. 1993. Cópia mimeo.

SHIFFRIN, Deborah. Approaches to discourse. Cambridge: Blackwell, 1994. 